\title{
Mechanical rotational thrombectomy with Rotarex system augmented with drug-eluting balloon angioplasty versus stenting for the treatment of acute thrombotic and critical limb ischaemia in the femoropopliteal segment
}

\author{
Paweł Latacz ${ }^{1}$, Marian Simka², Paweł Brzegowy³, Marek Piwowarczyk ${ }^{4}$, Tadeusz Popiela ${ }^{3}$ \\ ${ }^{1}$ Department of Neurology, Jagiellonian University Medical College, Krakow, Poland \\ ${ }^{2}$ Department of Anatomy, University of Opole, Opole, Poland \\ ${ }^{3}$ Chair of Radiology, Jagiellonian University Medical College, Krakow, Poland \\ ${ }^{4}$ Department of Vascular Surgery, University Hospital, Krakow, Poland
}

Videosurgery Miniinv 2019; 14 (2): 311-319

DOI: https://doi.org/10.5114/wiitm.2018.80006

\begin{abstract}
Introduction: Mechanical thrombectomy is an alternative to local thrombolysis for the treatment of severe ischaemia in the femoropopliteal segment, but stent implantation is usually required after this procedure. The use of drug-eluting balloons (DEBS) may overcome long-term problems associated with stents, but it remains unclear how often such a treatment is technically feasible and efficient.

Aim: This post hoc single-centre study was aimed at assessment of the feasibility, safety and efficacy of mechanical thrombectomy followed by application of DEBS.

Material and methods: Fifty-one patients, aged $69.1 \pm 11.6$ years, were managed for acute thrombotic or chronic critical ischaemia in the femoropopliteal segment using the Rotarex device. Following mechanical thrombectomy, on condition that there was no significant residual stenosis or dissection, lesions were managed with paclitaxel-coated $D E B s$, which was a desired strategy (24 patients). The remaining 25 patients underwent stent implantations, which was regarded as bailout treatment. Final follow-up was scheduled 12 months after the procedure.

Results: The primary-assisted patency rate after mechanical rotational thrombectomy with additional balloon angioplasty and/or stenting was $97.1 \%$ (49 patients). The early mortality rate was $2.0 \%$ (1 patient) and the amputation rate was $4.1 \%$ (2 patients). There were no late mortalities or limb amputations at 12-month follow-up, but significant restenoses occurred in $13(27.1 \%)$ patients. These restenoses were more frequent in patients who underwent stent implantation (45.5\%) than those managed with DEBs (12.5\%), and in patients managed for secondary lesions.

Conclusions: In selected patients mechanical rotational thrombectomy in the femoropopliteal segment followed by application of DEB is a safe, effective and long-lasting method of revascularisation.
\end{abstract}

Key words: critical ischaemia, stent, drug-eluting balloon, mechanical thrombectomy, acute limb ischaemia.

\section{Introduction}

Both acute thrombotic and chronic critical lower limb ischaemia are associated with high morbidity and mortality, and also with a high risk of unsuccessful revascularisation of the limb, requiring its amputation. Routine management of both types of limb ischaemia consists of anticoagulation followed 
by open surgical repair of occluded arteries (usually bypass grafting) [1-4]. Yet, such a treatment in patients with acute thrombotic ischaemia is associated with an amputation rate at the level of $10-70 \%$ and in-hospital mortality even as high as $15 \%$ [5]. In patients with critical limb ischaemia the amputation rate after surgical revascularization is at the level of $20-25 \%$ and the 2-year mortality rate in these patients is about $50 \%[2,5,6]$. Although local thrombolysis is associated with better clinical outcomes and currently it is preferred to surgical revascularization [7-10], not all occlusions can be opened by thrombolytic agents. Those primarily atherosclerotic poorly respond to thrombolysis. Moreover, even if thrombolysis is successful, these arteries usually re-occlude and stent implantation is often required, which carries another problem - in-stent stenosis or occlusion, primarily associated with intimal hyperplasia within the stent. Mechanical thrombectomy seems to be an alternative treatment modality [5, 11-14], but stent implantation with similar late problems is usually required after this endovascular procedure. The use of drug-eluting balloons (DEB) instead of stents may theoretically overcome clinical problems associated with stents, but it remains unclear how often such a treatment is technically feasible in these challenging patients and how efficient mechanical thrombectomy not augmented with stent implantations is in the long run.

\section{Aim}

This post hoc single-centre study was aimed at assessment of the feasibility, safety and efficacy of mechanical thrombectomy followed by application of DEBs for acute thrombotic or chronic critical ischaemia of the lower limbs in the femoropopliteal segment. We also analysed how often the use of rotational thrombectomy enabled an endovascular procedure not accompanied by stent implantation, and whether the utilisation of DEBs instead of stents was associated with a better clinical outcome.

\section{Material and methods}

We reviewed our register of endovascular interventions and identified patients with acute thrombotic ischaemia or chronic critical lower limb ischaemia due to occlusions in the femoropopliteal segment, who were managed using mechanical rotational thrombectomy (Rotarex ${ }^{\circledR}$ S device; Straub
Medical AG, Wangs, Switzerland). Technical success of mechanical rotational thrombectomy was defined in terms of absence of relevant post-procedural residual stenosis, with cutoff at the level of $50 \%$. Primary-assisted patency rate was defined as exempt from significant stenosis (cutoff at the level of 30\%) in the target artery following rotational thrombectomy and additional endovascular interventions during the primary procedure, such as balloon angioplasty and stenting.

Potential risks and benefits associated with such a procedure were discussed with the patients, and all patients gave their written informed consent. Clinical indications for mechanical rotational thrombectomy in our centre included:

- occlusions and/or critical stenoses of the distal femoral artery (distally from the profunda femoris artery) or the popliteal artery (with or without involvement of its branches);

- atherosclerotic, atherothrombotic and atheroaneurysmatic lesions;

- primary lesions and secondary lesions after previous balloon angioplasty or stent implantations.

Exclusion criteria comprised: highly calcified lesions, no adequate vascular access, contraindications for antiplatelet therapy, and lack of the patient's consent.

In this study we did not include patients presenting with arterial emboli. From June 2014 to November 2016 there were 51 eligible patients, 26 men and 25 women, with a mean age of $69.1 \pm 11.6$ years. Thirteen $(25.5 \%)$ patients were managed for acute non-embolic occlusions of the distal femoral artery and/or popliteal artery and its branches. Out of these patients, 6 (46.2\%) presented with an acutely occluded stent. Thirty-eight (74.5\%) patients were admitted to the hospital because of critical limb ischaemia resulting from atherothrombotic lesions at the same level as patients with acute ischaemia. In this group there were $5(13.2 \%)$ patients with thrombotic occlusions after balloon angioplasty and 18 (47.4\%) patients with chronically occluded stents. A majority of patients presented with grade 4 and 5 (21 and 25 patients, accordingly) of the Rutherford classification, and 5 patients presented with severe ischaemic ulcers (grade 6 in this classification). The demographic profile of both groups of patients and their co-morbidities are presented in Table I, while localisations and characteristics of arterial lesions are described in Table II. 
Table I. Clinical characteristics of patients

\begin{tabular}{|lccc|}
\hline Parameter & $\begin{array}{c}\text { All patients } \\
(n=51)\end{array}$ & $\begin{array}{c}\text { Critical limb ischaemia } \\
(n=38)\end{array}$ & $\begin{array}{c}\text { Acute non-embolic limb } \\
\text { ischaemia }(n=13)\end{array}$ \\
\hline Male/female ratio & $26 / 25(51.0 / 49.0 \%)$ & $17 / 21(44.7 / 55.3 \%)$ & $9 / 4(69.2 / 30.8 \%)$ \\
\hline Patients' age [years] & $69.1 \pm 11.6$ & $70.2 \pm 11.8$ & $67.9 \pm 15.5$ \\
\hline Diabetes mellitus type 2 & $20(39.2 \%)$ & $12(31.6 \%)$ & $8(61.5 \%)$ \\
\hline Cigarette smoking & $17(33.3 \%)$ & $13(34.2 \%)$ & $6(46.2 \%)$ \\
\hline Hypercholesterolaemia & $22(43.1 \%)$ & $16(42.1 \%)$ & $6(46.2 \%)$ \\
\hline Arterial hypertension & $44(86.3 \%)$ & $34(89.5 \%)$ & $10(76.9 \%)$ \\
\hline Family history cardiovascular disease & $9(17.6 \%)$ & $7(18.4 \%)$ & $2(15.4 \%)$ \\
\hline History of myocardial infarction & $11(21.6 \%)$ & $7(18.4 \%)$ & $4(30.8 \%)$ \\
\hline
\end{tabular}

Table II. Localisations and characteristics of arterial lesions

\begin{tabular}{|c|c|c|c|}
\hline Variable & $\begin{array}{l}\text { All patients } \\
\quad(n=51)\end{array}$ & $\begin{array}{l}\text { Critical limb ischaemia } \\
\qquad(n=38)\end{array}$ & $\begin{array}{l}\text { Acute non-embolic limb } \\
\text { ischaemia }(n=13)\end{array}$ \\
\hline Distal part of femoral artery & $12(23.5 \%)$ & $10(26.3 \%)$ & $2(15.4 \%)$ \\
\hline Popliteal artery & $14(27.5 \%)$ & $10(26.3 \%)$ & $4(30.8 \%)$ \\
\hline $\begin{array}{l}\text { Distal part of femoral artery and } \\
\text { popliteal artery }\end{array}$ & $16(31.4 \%)$ & $13(34.2 \%)$ & $7(53.8 \%)$ \\
\hline Popliteal artery and its branches & $7(13.7 \%)$ & $5(13.2 \%)$ & $2(15.4 \%)$ \\
\hline $\begin{array}{l}\text { Popliteal artery with aneurysmatic } \\
\text { dilatation }\end{array}$ & $3(5.9 \%)$ & $1(2.6 \%)$ & $2(15.4 \%)$ \\
\hline $\begin{array}{l}\text { Distal part of femoral artery and } \\
\text { popliteal artery with aneurysmatic } \\
\text { dilatation }\end{array}$ & $2(3.9 \%)$ & $2(5.3 \%)$ & 0 \\
\hline Mean length of the lesion [mm] & $247.0 \pm 135.8$ & $253.2 \pm 129.9$ & $303.8 \pm 140.0$ \\
\hline Thrombosis in the area of lesion & $34(66.7 \%)$ & $22(57.9 \%)$ & $12(92.3 \%)$ \\
\hline Total occlusion of the target artery & $44(86.3 \%)$ & $31(81.6 \%)$ & $13(100 \%)$ \\
\hline Degree of stenosis (\%) & $93 \pm 3.1$ & $92 \pm 2.2$ & 100 \\
\hline Ankle/brachial index at baseline & $0.2 \pm 0.1$ & $0.4 \pm 0.15$ & $0.2 \pm 0.15$ \\
\hline Primary lesion & $26(51.0 \%)$ & 19 (50.0\%) & $7(53.8 \%)$ \\
\hline Restenotic lesion & $25(49.0 \%)$ & $19(50.0 \%)$ & $6(46.2 \%)$ \\
\hline
\end{tabular}

Endovascular procedures were performed through ipsi- or contralateral femoral access. Before intervention all patients received $300 \mathrm{mg}$ of clopidogrel and $75 \mathrm{mg}$ of aspirin. During endovascular intervention patients were administered intravenously unfractionated heparin. Dosing of heparin depended on the duration of the procedure. We used $110 \mathrm{~cm}$ or $135 \mathrm{~cm}$ long $6 \mathrm{Fr}$ Rotarex ${ }^{\circledR} \mathrm{s}$ catheters. Firstly we navigated through the occluded segment with a 0.018 " guidewire and then performed 2-6 passages of the Rotarex system. After at least 2 passages of the rotational catheter, control catheter angiography was performed. If there was still over $50 \%$ stenosis, balloon angioplasty was performed. Afterwards, if there was no major residual stenosis (over 40\%) in the target artery and no significant dissection, this area was managed with paclitaxel-coated DEBs, such as Elutax SV (Aachen Resonance, Aachen, 
Germany) or Luminor (iVascular, Barcelona, Spain). This was a desired strategy, which was possible in 24 patients (49.0\%). In 25 (51.0\%) patients arteries revealed significant stenoses despite balloon angioplasty, or there were severe (grade $\mathrm{C}$ or higher) dissections. These patients underwent stent implantations, which was regarded as a bailout treatment. In addition, 6 (11.8\%) patients presenting with over $60 \%$ residual stenosis following balloon angioplasty and/or significant peripheral embolisation received alteplase intra-arterially (5 $\mathrm{mg}$ as a bolus, and then
$15 \mathrm{mg}$ during $12 \mathrm{~h}$ ). Details regarding results of rotational mechanical thrombectomy with the Rotarex system are given in Tables III and IV.

All patients were assessed before discharge from the hospital. They were discharged with the recommendation of dual antiplatelet therapy with aspirin (75-150 mg daily) and clopidogrel (75 mg daily). Their follow-ups were scheduled 30 days, 6 and 12 months after the procedure. Since there was 1 death and 2 amputations during the hospital stay, only 48 patients were followed up (24 patients managed

Table III. Results of rotational mechanical thrombectomy with Rotarex system in patients with acute vs. critical leg ischaemia

\begin{tabular}{|c|c|c|c|}
\hline Variables & $\begin{array}{l}\text { All patients } \\
(n=51)\end{array}$ & $\begin{array}{l}\text { Critical limb ischaemia } \\
\qquad(n=38)\end{array}$ & $\begin{array}{l}\text { Acute non-embolic limb } \\
\text { ischaemia }(n=13)\end{array}$ \\
\hline $\begin{array}{l}\text { Number of passages of the Rotarex } \\
\text { system }\end{array}$ & $3 \pm 2$ & $4 \pm 2$ & $3 \pm 1$ \\
\hline $\begin{array}{l}\text { Degree of stenosis after mechanical } \\
\text { thrombectomy (\%) }\end{array}$ & $54 \pm 15$ & $55 \pm 15$ & $45 \pm 13$ \\
\hline $\begin{array}{l}\text { Duration of mechanical } \\
\text { thrombectomy [min] }\end{array}$ & $5 \pm 2$ & $7 \pm 2$ & $5 \pm 2$ \\
\hline $\begin{array}{l}\text { Patients finally managed with } \\
\text { drug-eluting balloons }\end{array}$ & 24 & 19 & 5 \\
\hline $\begin{array}{l}\text { Degree of residual stenosis after } \\
\text { drug-eluting balloons (\%) }\end{array}$ & $13.5 \pm 4$ & $10.5 \pm 6$ & $12.5 \pm 9$ \\
\hline Patients finally managed with stents & 27 & 19 & 8 \\
\hline $\begin{array}{l}\text { Degree of residual stenosis after } \\
\text { stenting (\%) }\end{array}$ & $11.5 \pm 4$ & $10.5 \pm 6$ & $10.5 \pm 6$ \\
\hline $\begin{array}{l}\text { Ankle/brachial index at hospital } \\
\text { discharge }\end{array}$ & $0.73 \pm 0.10$ & $0.75 \pm 0.12$ & $0.75 \pm 0.14$ \\
\hline
\end{tabular}

Table IV. Results of rotational mechanical thrombectomy with Rotarex system in patients finally managed with drug-eluting balloons vs. those managed with stents.

\begin{tabular}{|lccc|}
\hline Variable & $\begin{array}{c}\text { All patients } \\
(n=51)\end{array}$ & $\begin{array}{c}\text { Patients managed with drug- } \\
\text { eluting balloons }(n=24)\end{array}$ & $\begin{array}{c}\text { Patients managed with } \\
\text { stents }(n=27)\end{array}$ \\
\hline $\begin{array}{l}\text { Patients presenting with critical limb } \\
\text { ischaemia }\end{array}$ & $38(74.5 \%)$ & $19(79.2 \%)$ & $19(70.4 \%)$ \\
\hline $\begin{array}{l}\text { Patients presenting with acute } \\
\text { non-embolic limb ischaemia }\end{array}$ & $13(25.5 \%)$ & $5(20.8 \%)$ & $4 \pm 1$ \\
\hline $\begin{array}{l}\text { Number of passages of the Rotarex } \\
\text { system }\end{array}$ & $4 \pm 2$ & $3 \pm 1$ & $45 \pm 13$ \\
\hline $\begin{array}{l}\text { Degree of stenosis after mechanical } \\
\text { thrombectomy (\%) }\end{array}$ & $47 \pm 20$ & $41 \pm 18$ & $10.5 \pm 6$ \\
\hline $\begin{array}{l}\text { Degree of residual stenosis after } \\
\text { balloon angioplasty and/or stenting (\%) }\end{array}$ & $14.3 \pm 6$ & $21.5 \pm 12$ & $0.70 \pm 0.12$ \\
\hline $\begin{array}{l}\text { Ankle/brachial index at hospital } \\
\text { discharge }\end{array}$ & $0.71 \pm 0.14$ & $0.72 \pm 14$ & \\
\hline
\end{tabular}


with DEBs and 22 patients who underwent stent implantation). At each visit patients underwent physical examination, evaluation of degree of limb ischaemia according to the Rutherford classification and duplex sonography of the recanalised arteries. Patients were also evaluated in a case of clinical worsening or delayed wound healing. Clinical worsening, restenosis revealed by sonographic examination and delayed healing of an arterial ulcer were the indications for control angiography and reintervention.

\section{Statistical analysis}

Multivariate stepwise backward conditional logistic regression analysis was used to determine independent predictors of restenosis/occlusion. The significance of this analysis was set at $p<0.05$.

\section{Results}

Technical success of mechanical rotational thrombectomy alone was achieved in 20 (19.6\%) patientsand there was a $97.1 \%$ primary-assisted patency rate (49 patients) after additional balloon angioplasty and stenting. In 2 (4.1\%) patients despite recanalisation of the target artery and stenting this procedure clinically failed and in both of them amputations of ischaemic limbs were performed during the hospital stay. Such an unfavourable outcome occurred in 1 patient presenting with acute thrombotic limb ischaemia and in 1 with chronic critical ischaemia. In both patients, in addition to occlusions of the distal femoral artery and popliteal artery, there were occlusions of the branches of the popliteal artery. There was one in-hospital death (mortality rate: $2.0 \%$ ). This patient died because of intracranial bleeding, which probably was associated with infusion of alteplase. There were local complications associated with mechanical thrombectomy in 5 (9.8\%) patients - distal embolisation in 4 patients, which was successfully managed with aspiration and local infusion of alteplase, and perforation of the artery in 1 case, which required implantation of a covered stent. There were neither mortalities nor major adverse events, such as myocardial infarction, stroke or limb amputation in all 48 remaining patients during 12 months of follow-up. At 12 month follow-up the clinical status of the majority of ischaemic limbs had improved. Only 1 (2.1\%) patient suffered from rest pain and 7 (14.6\%) patients from severe claudication. There were no patients presenting with isch- aemic ulcers. Details are given in Figure 1. In 13 patients $(27.1 \%$, excluding deceased and amputated patients) duplex sonography revealed occlusions or severe stenoses in the target arteries. These lesions primarily occurred in patients managed for secondary lesions (12 limbs). There was only 1 patient with restenosis after primary intervention. Also, restenoses and occlusions at follow-up were significantly more frequent in patients who underwent stent implantation (10 patients; $45.5 \%$ ) than in those managed with DEBs (3 patients; $12.5 \%$ ) - Figure 2. The risk of recurrent lesions was higher in patients with chronic critical lower limb ischaemia (11 patients; $30.6 \%$ ) than those managed for acute thrombotic occlusions (2 patients; $16.7 \%$ ). Details are described

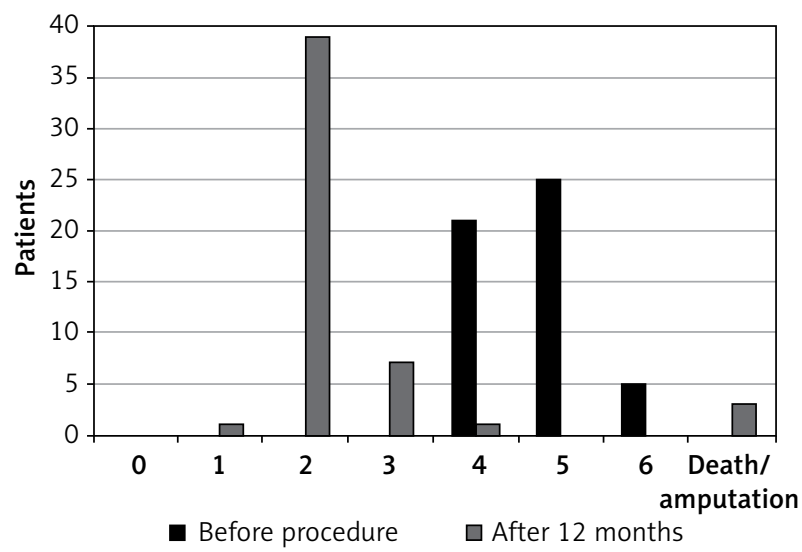

Figure 1. Degree of ischaemia according to the Rutherford classification before intervention and at 12-month follow-up

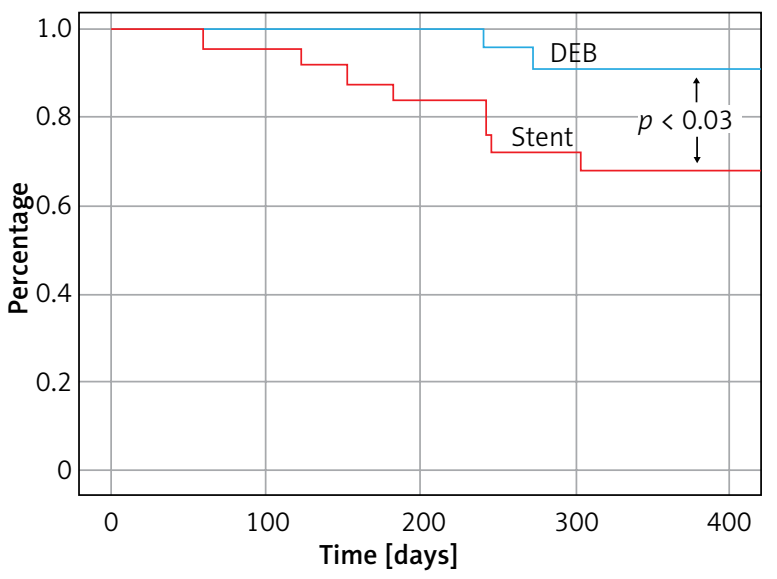

Figure 2. Kaplan-Meier event-free curves displaying the freedom from restenosis/reocclusion in patients managed with drug-eluting balloons (DEB) vs. those managed with stents 
Table V. Number of patients presenting with severe restenoses and occlusions at 12-month follow-up (patients who died or had their limbs amputated during first hospitalization were excluded)

\begin{tabular}{|lccc|}
\hline Parameter & All patients & $\begin{array}{c}\text { Critical limb } \\
\text { ischaemia }(n=36)\end{array}$ & $\begin{array}{c}\text { Acute non-embolic limb } \\
\text { ischaemia }(n=12)\end{array}$ \\
\hline All patients $(n=48)$ & $13(27.1 \%)$ & $11(30.6 \%)$ & $2(16.7 \%)$ \\
\hline Patients managed with drug-eluting balloons $(n=24)$ & $3(12.5 \%)$ & $3(15.8 \%)$ & 0 \\
\hline Patients managed with stents $(n=24)$ & $10(41.7 \%)$ & $8(47.1 \%)$ & $2(28.6 \%)$ \\
\hline Patients managed for primary lesions $(n=22)$ & $1(4.5 \%)$ & $1(6.7 \%)$ & 0 \\
\hline Patients managed for secondary lesions $(n=26)$ & $12(46.2 \%)$ & $10(47.6 \%)$ & $2(40.0 \%)$ \\
\hline
\end{tabular}

in Table V. The logistic regression analysis revealed that peripheral embolisation during the procedure and more than 4 passages of the Rotarex system were significantly associated with a higher risk of restenosis/occlusion (hazard ratio: 5.6 and 5.0; $p=$ 0.018 and 0.025 respectively).

\section{Discussion}

In this post-hoc analysis we have demonstrated that the majority of severe atherothrombotic lesions in the femoropopliteal segment that result in acute or chronic critical limb ischaemia, and are not highly calcified, can be reopened using mechanical rotational thrombectomy. In our patient series the primary-assisted patency rate after thrombectomy augmented by balloon angioplasty and stenting was as high as $97.1 \%$. in the in-hospital amputation rate was $4.1 \%$. Such management was also safe. In-hospital mortality was $2.0 \%$, which was significantly lower than after an open surgical revascularization. Moreover, in $49 \%$ of patients it was possible to avoid stent implantation and instead to manage the area of occlusion with DEB.

Analysis of the clinical outcome of our patients at 12-month follow-up demonstrated that mechanical rotational thrombectomy with the Rotarex system followed by DEB was not inferior to such a thrombectomy assisted by stent implantation. Actually, the results after DEB were better; there were fewer restenoses and no amputations. Yet, stents were implanted in patients with more advanced pathology and therefore these differences should be interpreted with caution. Similarly, although we identified peripheral embolisation during the procedure and more than 4 passages of the Rotarex system as risk factor of reocclusion, these events were probably predictors of more advanced arterial disease, and thus the risk of reocclusion in these patients was higher. Similarly worse late results in patients who required local fibrinolysis in addition to mechanical thrombectomy have already been reported by Kronlage [5].

Large epidemiological studies have revealed a significant risk of major amputation and/or mortality associated with open surgical revascularization for acute and critical leg ischaemia [1-3, 15]. Consequently, local fibrinolysis or endovascular thrombectomy is currently suggested to be a preferred treatment modality [16-20]. In the large study by Freitas et al., who managed with Rotarex 525 patients presenting with acute and subacute ischaemia, with an average length of occluding lesions of $159 \mathrm{~mm}$, there was $1.1 \%$ mortality and a $2.3 \%$ major amputation rate during 30-day follow-up. Adverse events associated with the treatment occurred in $6.9 \%$ of patients and mortality after 1 year was 8\% [19]. Similar outcomes were reported by Kronlage et al. They managed 202 patients and in this group amputation-free survival was $94.3 \%$ [5].

Although mechanical thrombectomy with the Rotarex system has been demonstrated to be both relatively safe and efficient [5, 7-9, 14, 16-19], it remains to be established how to optimize such treatment. Even if short-term results are encouraging, long-term patency rates in the femoropopliteal segment after standard balloon angioplasty or stent implantation are relatively low. The 1-year reocclusion rate after balloon angioplasty is at the level of $60 \%$ [21-28]. Stents do not seem to be a proper solution either. When implanted in this part of the arterial system, especially in the distal part of the popliteal artery or in its branches, a significant proportion of currently available stents occlude in the long run, either because of a fracture, or due to thrombosis and intimal hyperplasia [21-29]. Although novel wire-in- 
terwoven Nitinol or helically shaped stents, exhibiting a swirling flow, try to overcome these problems, they are not yet routinely used and their actual longterm advantage remain to be proven [30-35]. On the other hand, long-term patency rates in the femoropopliteal segment after DEBs are higher than after standard balloon angioplasty [36-47], while the problems associated with stents are avoided.

The results of our study suggest that the use of DEB after mechanical thrombectomy for thrombotic acute or critical leg ischaemia resulting from arterial occlusion in the femoropopliteal segment could be a desired treatment strategy. However, it should be emphasized that it was a retrospective analysis and the groups of patients were not fully comparable. A larger prospective study should be designed and performed in order to fully compare the clinical value of DEBs with stents in these challenging patients. Also, probably some novel area-dedicated stents (such as the aforementioned helically shaped ones) should be applied in such a trial.

\section{Conclusions}

The short and intermediate term results from this nonrandomised study indicate that the combination of mechanical thrombectomy with DEB is safe and feasible for the treatment of intermediate to long superficial femoral artery/popliteal artery lesions in selected patients with severe limb ischaemia. The DEB group had higher rates of primary patency and freedom from restenosis than the group of patients with stent implantation.

\section{Conflict of interest}

The authors declare no conflict of interest.

\section{References}

1. Hirsch AT, Haskal ZJ, Hertzer NR, et al. ACC/AHA 2005 guidelines for the management of patients with peripheral arterial disease (lower extremity, renal, mesenteric, and abdominal aortic): executive summary a collaborative report from the American Association for Vascular Surgery/Society for Vascular Surgery, Society for Cardiovascular Angiography and Interventions, Society for Vascular Medicine and Biology, Society of Interventional Radiology, and the ACC/AHA Task Force on Practice Guidelines (Writing Committee to Develop Guidelines for the Management of Patients With Peripheral Arterial Disease) endorsed by the American Association of Cardiovascular and Pulmonary Rehabilitation; National Heart, Lung, and Blood Institute; Society for Vascular Nursing; TransAtlantic Inter-So- ciety Consensus; and Vascular Disease Foundation. J Am Coll Cardiol 2006; 47: 1239-312.

2. Norgren L, Hiatt WR, Dormandy JA, et al. TASC II Working Group. Inter-Society Consensus for the Management of Peripheral Arterial Disease (TASC II). J Vasc Surg 2007; 45 Suppl S: S5-67.

3. Rutherford RB, Becker GJ. Standards for evaluating and reporting the results of surgical and percutaneous therapy for peripheral arterial disease. J Vasc Interv Radiol 1991; 2: 169-74.

4. Schlager O, Dick P, Sabeti S, et al. Long-segment SFA stentingthe dark sides: in-stent restenosis, clinical deterioration, and stent fractures. J Endovasc Ther 2005; 12: 676-84.

5. Kronlage M, Printz I, Vogel B, et al. A comparative study on endovascular treatment of (sub)acute critical limb ischemia: mechanical thrombectomy vs thrombolysis. Drug Des Devel Ther 2017; 11: 1233-41.

6. Davies MG. Criticial limb ischemia: epidemiology. Methodist Debakey Cardiovasc J 2012; 8: 10-4.

7. Ouriel K, Shortell CK, DeWeese JA, et al. A comparison of thrombolytic therapy with operative revascularization in the initial treatment of acute peripheral arterial ischemia. J Vasc Surg 1994; 19: 1021-30.

8. Weaver FA, Comerota AJ, Youngblood M, et al. Surgical revascularization versus thrombolysis for nonembolic lower extremity native artery occlusions: results of a prospective randomized trial. The STILE Investigators. Surgery versus Thrombolysis for Ischemia of the Lower Extremity. J Vasc Surg 1996; 24: 513-21.

9. Ouriel K, Veith FJ, Sasahara AA. Thrombolysis or peripheral arterial surgery: phase I results. TOPAS Investigators. J Vasc Surg 1996; 23: 64-73.

10. Swischuk JL, Fox PF, Young K, et al. Transcatheter intraarterial infusion of rt-PA for acute lower limb ischemia: results and complications. J Vasc Interv Radiol 2001; 12: 423-30.

11. Lagana D, Carrafiello G, Lumia D, et al. Recanalisation of thrombotic arterial occlusions with rotational thrombectomy. Radiol Med 2011; 116: 932-44.

12. Wissgott C, Kamusella P, Andresen R. Recanalization of acute and subacute venous and synthetic bypass-graft occlusions with a mechanical rotational catheter. Cardiovasc Intervent Radiol 2013; 36: 936-42.

13. Wissgott C, Kamusella P, Richter A, et al. Mechanical rotational thrombectomy for treatment thrombolysis in acute and subacute occlusion of femoropopliteal arteries: retrospective analysis of the results from 1999 to 2005. Rofo 2008; 180: 325-31.

14. Lichtenberg M, Stahlhoff W, Boese D, Hailer B. Twelve months outcome after percutaneous mechanical thrombectomy for treatment of acute femoropopliteal bypass occlusion. Cardiovasc Interv Ther 2013; 28: 178-83.

15. Baril DT, Patel VI, Judelson DR, et al. Vascular Study Group of New England. Outcomes of lower extremity bypass performed for acute limb ischemia. J Vasc Surg 2013; 58: 949-56.

16. Wissgott C, Kamusella P, Andresen R. Treatment of femoropopliteal stenoses and occlusions with mechanical rotational catheters: comparison of results with the Rotarex and Pathway devices. J Cardiovasc Surg 2012; 53: 177-86.

17. Zeller T, Frank U, Bürgelin $\mathrm{K}$, et al. Early experience with a rotational thrombectomy device for treatment of acute and sub- 
acute infra-aortic arterial occlusions. J Endovasc Ther 2003; 10: 322-31.

18. Dys K, Drelichowska-Durawa J, Dolega-Kozierowski B, et al. Mechanical thrombectomy using Rotarex system and stent-instent placement for treatment of distal femoral artery occlusion secondary to stent fracture - a case report and literature review. Pol J Radiol 2013; 78: 74-9.

19. Freitas B, Steiner S, Bausback Y, et al. Rotarex mechanical debulking in acute and subacute arterial lesions: single-center experience with 525 patients. Angiology 2017; 68: 233-41.

20. Hirsch AT, Haskal ZJ, Hertzer NR, et al. ACC/AHA 2005 Practice Guidelines for the management of patients with peripheral arterial disease (lower extremity, renal, mesenteric, and abdominal aortic). Circulation 2006; 113: e463-5.

21. Rocha-Singh KJ, Jaff MR, Crabtree TR, et al. Performance goals and endpoint assessments for clinical trials of femoropopliteal bare nitinol stents in patients with symptomatic peripheral arterial disease. Catheter Cardiovasc Interv 2007; 69: 910-9.

22. Dick P, Wallner H, Sabeti S, et al. Balloon angioplasty versus stenting with nitinol stents in intermediate length superficial femoral artery lesions. Catheter Cardiovasc Interv 2009; 74: 1090-5.

23. Schillinger M, Sabeti S, Loewe C, et al. Balloon angioplasty versus implantation of nitinol stents in the superficial femoral artery. N Engl J Med 2006; 354: 1879-88.

24. Drelicharz L, Belowski A, Krzanowski M, et al. Safety and efficacy of endovascular treatment of chronic ischemia of the lower limbs in 6-months follow-up. Acta Angiologica 2013; 19: 18-35.

25. Chowdhury MM, McLain AD, Twine CP. Angioplasty versus bare metal stenting for superficial femoral artery lesions. Cochrane Database Syst Rev 2014; 6: CD006767.

26. Diehm N, Baumgartner I. Routine stent implantation vs. percutaneous transluminal angioplasty in femoropopliteal artery disease: a meta-analysis of randomized controlled trials. Eur Heart J 2009; 30: 3083-4.

27. Twine CP, Coulston J, Shandall A, McLain AD. Angioplasty versus stenting for superficial femoral artery lesions. Cochrane Database Syst Rev 2009; 2: CD006767.

28. Laird JR, Katzen BT, Scheinert D, et al. Nitinol stent implantation vs. balloon angioplasty for lesions in the superficial femoral and proximal popliteal arteries of patients with claudication: three-year follow-up from the RESILIENT randomized trial. J Endovasc Ther 2012; 19: 1-9.

29. Laird JR, Katzen BT, Scheinert D, et al. Nitinol stent implantation versus balloon angioplasty for lesions in the superficial femoral artery and proximal popliteal artery: twelve-month results from the RESILIENT randomized trial. Circ Cardiovasc Interv 2010; 3: 267-276.

30. Scheinert D, Grummt L, Piorkowski M, et al. A novel self- expanding interwoven nitinol stent for complex femoropopliteal lesions: 24-month results of the SUPERA SFA registry. J Endovasc Ther 2011; 18: 745-52.

31. Chan YC, Cheng SW, Ting AC, et al. Primary stenting of femoropopliteal atherosclerotic lesions using new helical interwoven nitinol stents. J Vasc Surg 2014; 59: 384-91.

32. Stecko W, Rogala W, Feldo M, et al. Results of endovascular treatment of iliac and femoral symptomatic lesions. Identification of re-intervention risk factors. Acta Angiol 2017; 23: 115-23.
33. Garcia L, Jaff MR, Metzger C, et al. Wire-interwoven nitinol stent outcome in the superficial femoral and proximal popliteal arteries: twelve-month results of the SUPERB trial. Circ Cardiovasc Interv 2015; 8: pii: e000937.

34. de Boer SW, van den Heuvel DAF, de Vries-Werson DAB, et al. Short-term results of the RAPID randomized trial of the legflow paclitaxel-eluting balloon with supera stenting vs supera stenting alone for the treatment of intermediate and long superficial femoral artery lesions. J Endovasc Ther 2017; 24: 783-92.

35. Sullivan TM, Zeller T, Nakamura M, et al. Swirling flow and wall shear: evaluating the biomimics $3 \mathrm{~d}$ helical centerline stent for the femoropopliteal segment. Int J Vasc Med 2018; 2018: 9795174.

36. Fusaro M, Cassese S, Ndrepepa G, et al. Paclitaxel-coated balloon or primary bare nitinol stent for revascularization of femoropopliteal artery: a meta-analysis of randomized trials versus uncoated balloon and an adjusted indirect comparison. Int J Cardiol 2013; 168: 4002-9.

37. Buszman PP, Milewski K, Zurakowski A, et al. Experimental evaluation of pharmacokinetic profile and biological effect of a novel paclitaxel microcrystalline balloon coating in the iliofemoral territory of swine. Catheter Cardiovasc Interv 2014; 83: 325-33.

38. Tepe G, Laird J, Schneider P, et al. Drug-coated balloon versus standard percutaneous transluminal angioplasty for the treatment of superficial femoral and popliteal peripheral artery disease. Circulation 2015; 131: 495-502.

39. Giacoppo D, Cassese S, Harada Y, et al. Drug-coated balloon versus plain balloon angioplasty for the treatment of femoropopliteal artery disease: an updated systematic review and meta-analysis of randomized clinical trials. JACC Cardiovasc Interv 2016; 9: 1731-42.

40. Katsanos K, Spiliopoulos S, Paraskevopoulos I, et al. Systematic review and meta-analysis of randomized controlled trials of paclitaxel-coated balloon angioplasty in the femoropopliteal arteries: role of paclitaxel dose and bioavailability. J Endovasc Ther 2016; 23: 356-70.

41. Rosenfield K, Jaff MR, White CJ, et al. Trial of a paclitaxel-coated balloon for femoropopliteal artery disease. N Engl J Med 2015; 373: $145-53$.

42. Laird JR, Schneider PA, Tepe G, et al. Durability of treatment effect using a drug-coated balloon for femoropopliteal lesions: 24-month results of IN.PACT SFA. J Am Coll Cardiol 2015; 66: 2329-38.

43. Giacoppo D, Cassese S, Harada Y, et al. Drug-coated balloon versus plain balloon angioplasty for the treatment of femoropopliteal artery disease: an updated systematic review and meta-analysis of randomized clinical trials. JACC CardiovasC Interv 2016; 9: 1731-42.

44. Jongsma $\mathrm{H}$, Bekken JA, de Vries JP et al. Drug-eluting balloon angioplasty versus uncoated balloon angioplasty in patients with femoropopliteal arterial occlusive disease. J Vasc Surg 2016; 64: 1503-14

45. Werk M, Langner S, Reinkensmeier B, et al. Inhibition of restenosis in femoropopliteal arteries: paclitaxel-coated versus uncoated balloon: femoral paclitaxel randomized pilot trial. Circulation 2008; 118: 1358-65. 
46. Scheinert D, Duda S, Zeller T, et al. The LEVANT I (Lutonix Paclitaxel-Coated Balloon for the Prevention of Femoropopliteal Restenosis) trial for femoropopliteal revascularization: firstin-human randomized trial of low-dose drug-coated balloon versus uncoated balloon angioplasty. JACC Cardiovasc Interv 2014; 7: 10-9.

47. Dake MD, Ansel GM, Jaff MR, et al. Durable clinical effectiveness with paclitaxel-eluting stents in the femoropopliteal artery: 5-year results of the Zilver PTX randomized trial. Circulation 2016; 133: 1472-83.

Received: 24.07.2018, accepted: 23.09.2018. 